man beliebige Legierungen in glattem Metallüberzuge herstellen, der ebenso schön ist, als wenn man reines Eisen, Nickel oder Kobalt herstellt. Ich habe mir damals in dieser Sache sehr viel Mühe gegeben, weil ich die so wertvollen Eisen- und Nickellegierungen elektrolytisch herzustellen gedachte, bin aber auf die Schwierigkeit gestossen, die Herr Prof. Küster erwähnt hat, dass die Mengen Eisen und Nickel in der Legierung mit der Fortdauer der Elektrolyse variierten, so dass ich die Sache aufgegeben habe. Aber möglicherweise ist der Umstand, dass Eisen, Nickel oder Kobalt sich gegenseitig $\mathrm{zu}$ lösen vermögen, eine Beobachtung, die geeignet ist, die Erscheinung zu deuten.

Präsident: Wünscht sonst noch jemand das Wort? - Wenn dies nicht der Fall ist, so erteile ich Herrn Dr. Bredig das Wort zu seinem Vortrage.

Herr Dr. G. Bredig-Leipzig:

\title{
DAS AMPĖREMANOMETER.
}

\section{(Nach gemeinschaftlichen Versuchen mit Herrn O. Hahn.)}

Meine Herren! Das Knallgasvoltameter ist als Ampèremeter wohl hauptsächlich deshalb so unbequem, weil zu jeder Ablesung eine Zeitmessung und eine Gasvolummessung gehört. Man will ja die Geschwindigkeit, mit der sich das Knallgas entwickelt, messen. Nun giebt es aber ein leichtes Mittel, das neuerdings auch von Ostwald bei seinen bekannten Chromversuchen angewandt worden ist, die Entwicklungsgeschwindigkeit eines Gases als Druck zu messen. $\mathrm{Zu}$ diesem $Z$ wecke braucht man das Gefäss nur zu verschliessen und das Gas nur an einer Stelle durch eine Kapillare entweichen zu lassen. Der an einem Manometer messbare Ueberdruck im Apparate wird dann bei gegebener Länge und gegebener Weite der Kapillaren mit der Entwicklungsgeschwindigkeit des Gases steigen, und zwar wird er nach der Poiseuilleschen Formel bei geringen Ueberdrucken dieser Entwicklungsgeschwindigkeit annähernd proportional sein.

$\mathrm{Da}$ die Entwicklungsgeschwindigkeit des Knallgases in dem Voltameter auch der Stromstärke proportional ist, so wird hier ein geringer, durch eine Kapillare erzeugter Ueberdruck gegen die Atmosphäre sehr annähernd proportional der Stromstärke sein. Wir können also so die Ampère in Drucken messen.

Nach diesem Prinzip haben wir unser Ampèremanometer konstruiert, das nur als einfaches, billiges Schaltinstrument für chemische Laboratorienzwecke, nicht als präzises Messinstrument gedacht ist, wie ich gleich vorausschicken will.

Der einfache Apparat hat folgende Form:

Die Zersetzungszelle besteht aus einem Glasgefäss $a$ (Fig. 98), welches nahezu vollständig mit
Natronlauge $(2 \%)$ gefüllt wird. In dieselbe tauchen die beiden konzentrischen cylindrischen Nickelelektroden $b$ und $c$, die voneinander durch ein paar eingeschobene Glasstäbe isoliert sind. Nickeldrähte bewirken durch den gasclichten Stopfen der Flasche hindurch die Zuführung des Stromes.

Das elektrolytisch entwickelte Knallgas entweicht durch das Glasrohrd und tritt in die Erweiterung $e$, in welcher es durch Watte filtriert und so von mitgerissenem Flüssigkeitsstaub gereinigt wird. Die Watte ist öfter zu erneuern. Alsdann entweicht das Gas durch die Kapillare $f$, deren Länge bei passender Weite sich sehr leicht so abgleichen lässt, dass das mit $d$ kommunizierende Wassermanometer $g$ bei I Amp. Strom zum Beispiel auf der verschieb-

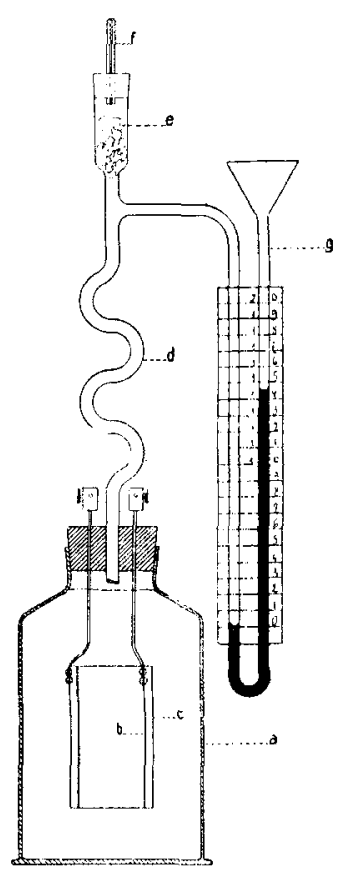

Fig. 98 . baren Skala gerade den Wasserdruck I cm anzeigt. Will man den Messbereich und damit die Empfindlichkeit ändern, so braucht man nur eine anders abgeglichene Kapillare $f$ in $e$ an Stelle der ersteren zu setzen, so dass jetzt z. B. bei I Amp. Strom ein Druck von Io cm Wassersäule entsteht. Das Instrument ist also durch einfache Auswechselung der Kapillare zehnmal empfindlicher geworden. Die 
Abgleichung passender Röhren ist eine sehr einfache Arbeit, wenn man dieselben zuerst beim Eichen etwas zu lang nimmt und dem Drucküberschuss proportionale Verkürzungen derselben vornimmt. Die Röhren lassen sich leicht mit Wasser, Alkohol und Aether reinigen, falls sie einmal innerlich betauen, was selten vorkommt und leicht bemerkt wird.

Ein solches Ampèremanometer gab z. B. folgende Ablesungen:

\begin{tabular}{|c|c|c|}
\hline & Ainp. & $\begin{array}{l}\text { Wasserdruck } \\
\text { in } \mathrm{cm}\end{array}$ \\
\hline \multicolumn{3}{|c|}{ Mit Kapillare Nr. 2 : } \\
\hline \multirow[t]{2}{*}{ am I. Tage. } & 10,0 & 9,7 \\
\hline & 9,9 & 9,9 \\
\hline \multirow[t]{3}{*}{ am 2. Tage } & 9,5 & 9,2 \\
\hline & 7,7 & 7,5 \\
\hline & 4,7 & 4,6 \\
\hline am 3. Tage & 7,0 & 7,0 \\
\hline \multicolumn{3}{|c|}{ Mit Kapillare Nr. 4 : } \\
\hline & $\mathrm{I}, 44$ & I 4,3 \\
\hline & $\mathrm{I}, \mathrm{I} 4$ & I 1,3 \\
\hline & 0,40 & 3,9 \\
\hline & 0,19 & $I, 9$ \\
\hline
\end{tabular}

Nach Versuchen von Herrn Hahn gilt für feuchtes Knallgas bei Zimmertemperatur annähernd die Formel:

$$
P=\frac{8,4 \cdot 10^{-4} \cdot l \cdot i}{r^{4}},
$$

worin $P$ den Ueberdruck in Centimetern Wassersäule, $i$ die Stromstärke in Ampère, $l$ die Länge der Kapillare in Centimetern, $r$ den Radius der Kapillare in Millimetern bedeuten.

Da die innere Reibung der Gase bekanntlich mit der Temperatur zunimmt, so haben wir auch den Einfluss der Temperatur untersucht. Der Temperaturkoëffizient beträgt ungefähr $+0,56 \%$. Die üblichen Schwankungen der Zimmertemperatur dürften also kaum grössere Fehler als $5 \%$ hervorbringen, Fehler, welche unser Apparat ohnehin in den Einstellungen zeigt.

\section{I. ÜBER DAS VERHALTEN DER MA}

Elektrolysiert man Manganosalze unter Verwendung einer unangreifbaren Anode, so kamn man Manganisalze, Braunstein oder Uebermangansäure erhalten, je nach Art und Menge der Säure und Wahl der sonstigen Versuchsbedingungen. Die Bezcichnung Braunstein ist
Das Instrument, dessen Empfindlichkeit nicht über I $\mathrm{cm}$ Wasserdruck pro o, I Amp. gesteigert wurde, hat sich bei analytischen und synthetischen Elektrolysen, bei denen eine Genauigkeit der Strommessung bis auf $5 \%$ genügt, gut bewährt. Die gewöhnlichen Schaltinstrumente mit Spule und Magnet sind meist nicht viel genauer und jedenfalls viel teurer und leichter zu beschädigen, als unser Apparat, der wohl auch pädagogischen Wert besitzt.

Unser Ampèremanometer verbraucht freilich I,6 bis 2 Volt Spannung, indessen müssen ohnehin in den chemischen Laboratorien solche Spannungsüberschüsse in den Regulierwiderständen oft absichtlich vermützt werden 1).

Präsident: Ich möchte mir die Frage erlauben, ob nicht Störungen eintreten können. Der Wasserstoff nimmt flüssige Teilchen mit, dic durch den Baumwollpfropfen getrieben werden; entwickelt sich da keine Reibung?

Herr Dr. Bredig: Wenn die Stromstärken nicht zu gross sind, merkt man davon nichts. Bei sehr hohen Stromstärken tritt eine kleine Differenz ein, die übrigens nur dann über $2 \mathrm{~mm}$ hinausgeht, wenn die Watte zu fest gestopft ist. Letzteres ist aber durchaus nicht nötig; denn man kann die Watte ziemlich locker stopfen und sie wirkt gleichwohl völlig filtrierend auf die Flüssigkeit. Natürlich ist zu empfehlen, die Watte von Zeit zu Zeit zu erneuern; sie hält übrigens sehr lange vor.

Präsident: Meldet sich sonst noch jemand zum Wort? Wenn nicht, so schreite ich weiter und ersuche Herrn Professor Elbs das Wort zu seinem Vortrage zu nehmen.

Herr Prof. Dr. K. Elbs-Giessen:

1) Die Firma Franz Hugershoff in Leipzig, Karolinenstrasse, hat es übernommen, fertige Kapillaren für verschiedene Stromstärken und auch den kompletten Apparat zu liefern.

\section{MANGANOSALZE AN DER ANODE.}

hier als Sammelname für alle diejenigen braunen Niederschläge zu verstehen, welche Hydrate oder sonstige Abkömmlinge des Mangansuperoxydes sind.

Man muss streng unterscheiden zwischen den Bedingungen, unter welchen Uebermangan- 